\title{
Advanced imaging techniques for neuro-oncologic tumor diagnosis, with an emphasis on PET-MRI imaging of malignant brain tumors
}

\author{
Wynton B. Overcast ${ }^{1} \cdot$ Korbin M. Davis ${ }^{1} \cdot$ Chang Y. Ho ${ }^{2} \cdot$ Gary D. Hutchins ${ }^{3} \cdot$ Mark A. Green $^{3}$. \\ Brian D. Graner ${ }^{2}$. Michael C. Veronesi ${ }^{4}$
}

Accepted: 11 January 2021 / Published online: 18 February 2021

(C) The Author(s) 2021

\begin{abstract}
Purpose of Review This review will explore the latest in advanced imaging techniques, with a focus on the complementary nature of multiparametric, multimodality imaging using magnetic resonance imaging (MRI) and positron emission tomography (PET). Recent Findings Advanced MRI techniques including perfusion-weighted imaging (PWI), MR spectroscopy (MRS), diffusionweighted imaging (DWI), and MR chemical exchange saturation transfer (CEST) offer significant advantages over conventional MR imaging when evaluating tumor extent, predicting grade, and assessing treatment response. PET performed in addition to advanced MRI provides complementary information regarding tumor metabolic properties, particularly when performed simultaneously. ${ }^{18} \mathrm{~F}$-fluoroethyltyrosine (FET) PET improves the specificity of tumor diagnosis and evaluation of post-treatment changes. Incorporation of radiogenomics and machine learning methods further improve advanced imaging.

Summary The complementary nature of combining advanced imaging techniques across modalities for brain tumor imaging and incorporating technologies such as radiogenomics has the potential to reshape the landscape in neuro-oncology.
\end{abstract}

Keywords Brain tumor · Advanced MRI · Amino acid PET · FET · Hybrid PET/MRI · Radiogenomics · Glioma · Glioblastoma · Metastasis · High-grade malignancy $\cdot$ Progression $\cdot$ Pseudoprogression $\cdot$ Radiation necrosis $\cdot$ Pseudoresponse $\cdot$ Treatment-related change $\cdot$ Tumor grading $\cdot$ Perfusion-weighted imaging $\cdot$ Diffusion-weighted imaging $\cdot$ Chemical exchange saturation transfer . MR spectroscopy $\cdot$ Radiomics

\section{Introduction}

Primary central nervous system tumors have one of the leading cancer incidence rates across patients of all ages with nearly 400,000 US cases reported between 2012 and 2016 [1]. Greater than two-thirds are considered benign; the remaining malignant tumors contribute to significant morbidity and mortality [2]. Secondary brain tumors, including brain metas-

This article is part of the Topical Collection on Neuro-oncology

Highlighted Studies: This study by Galldiks is a highly cited paper for its incorporation of dynamic analysis of FET PET imaging along with static values to determine tumor progression or recurrence. The findings have been reproduced over several subsequent studies.

Galldiks N, Stoffels G, Filss C, et al. The use of dynamic O-(2-18F-fluoroethyl)-1-tyrosine PET in the diagnosis of patients with progressive and recurrent glioma. Neuro Oncol. 2015;17(9):1293-1300. doi:10.1093/neuonc/nov088

PET/MRI

The power of hybrid FET PET/MRI was harnessed to demonstrate glioma biodistribution which exceeded contrast-enhanced MR imaging. This very recent paper corroborates prior publications that point to using FET volume rather than contrast volume for surgical planning. Song S, Cheng Y, Ma J, et al. Simultaneous FET-PET and contrast-enhanced MRI based on hybrid PET/MR improves delineation of tumor spatial biodistribution in gliomas: a biopsy validation study. Eur J Nucl Med Mol Imaging. 2020;47(6):1458-1467. doi:10.1007/s00259-019-04656-2

Hybrid FET PET/MRI imaging was combined with textural analysis in radiomics to accurately predict IDH status. This paper points to the complementary nature of all tools combined.

Lohmann P, Lerche C, Bauer EK, et al. Predicting IDH genotype in gliomas using FET PET radiomics. Sci Rep. 2018;8(1):13328. Published 2018 Sep 6. doi:10.1038/s41598-018-31806-7

Michael C. Veronesi

mverones@iu.edu

Extended author information available on the last page of the article 
tases, are ten-fold more frequent and have a major impact on outcome data [3]. Although significant advancements have been made in the management of brain tumor patients, highgrade malignancies remain difficult to treat. For instance, the life expectancy of patients with glioblastoma (GBM) was around 20 months with addition of tumor-treating fields to the standard of care therapy regimen [4]. More broadly, only $23.5 \%$ of patients with a malignant brain or spine tumor are expected to still be alive after 5 years, based on data compiled from the Central Brain Tumor Registry between the years of 2013-2017 [5].

The critical role of advanced imaging in the diagnosis, treatment, and subsequent management of brain tumors is discussed in this review. Conventional MRI is useful for initial assessment, but can present limitations when evaluating tumor extent, predicting grade, and assessing treatment response. Advanced MRI techniques such as perfusion-weighted imaging (PWI), MR spectroscopy (MRS), diffusion-weighted imaging (DWI), and MR chemical exchange saturation transfer (CEST) are helping address this shortcoming. PWI shows great potential, especially for determining tumor progression versus treatment related change, but standardization is needed across institutions. While MRS has shown high accuracy in publications, clinical application poses challenges. Diagnostic confidence can be improved when combining with additional MR sequences and modalities. DWI can contribute to tumor characterization in select circumstances. Newer quantitative diffusion tensor imaging (DTI) techniques that measure the degree of cellularity are in development. CEST is still in the advanced clinical research and development phase. CEST has great potential for patients who cannot receive MRI contrast since it relies on intrinsic properties of mobile phase proteins in the cell. PET imaging provides complementary information regarding tumor metabolic properties and can be performed with or combined with advanced MRI. Amino acid PET is emerging as the key to diagnostic specificity. The overall direction of amino acid PET imaging favors the use of ${ }^{18} \mathrm{~F}$ fluoroethyltyrosine (FET) given its additional well characterized properties for both static and dynamic tumor imaging. The typical conclusion of publications that utilized separately obtained PET and MRI points to the superiority of hybrid PET/MRI systems. Recent papers using hybrid PET/MRI systems highlighted in this review strengthen these conclusions. Finally, we briefly discuss a complementary role for radiogenomics in neuro-oncologic disease management.

\section{Magnetic resonance imaging}

\section{Conventional MRI}

For many years, conventional MRI has been the standard modality to diagnose and localize brain tumors, perform stereotactic biopsy, plan surgical resection, and distinguish post-treatment changes from recurrent tumor. Conventional MRI sequences include pre- and post-contrast T1-weighted, T2-weighted, T2-based fluid attenuation inversion recovery (FLAIR), DWI with apparent diffusion coefficient (ADC), and either susceptibility-weighted or gradient echo imaging. The Response Assessment in Neuro-Oncology (RANO) working group has defined many of the metrics for tumor analysis in conventional MRI. Measurable disease requires a bidimensional measurement of a contrast enhancing lesion with margins that are clearly discernable. The measurements should be perpendicular and at least $10 \mathrm{~mm}$ in length, visible on at least two axial slices. Non-measurable disease applies to lesions that are less than $10 \mathrm{~mm}$ have unclear surgical margins or where only a single dimensional measurement can be made. In 2010, the RANO group added non-enhancing mass-like T2/FLAIR signal as part of the non-measurable criteria [6]. The RANO criteria has more limited application when discerning true tumor extent or tumor progression from treatment-related changes, which includes pseudoprogression, radiation necrosis, and pseudoresponse [7]. Extensive work is being done to overcome limitations of conventional imaging. Development of PWI, MRS, DWI, and CEST are discussed in the next section.

\section{MR Perfusion-weighted Imaging}

PWI is a technique that measures tumor vascularity by dynamically evaluating tissue after either exogenous contrast administration or through non-invasive labeling of endogenous water molecules. The three main perfusion techniques available clinically include dynamic susceptibility contrast (DSC), dynamic contrast enhancement (DCE), and arterial spin labeling (ASL). The most used technique, DSC, takes advantage of signal loss amplification inherent in susceptibility-weighted sequences with passage of paramagnetic gadolinium through the tissue. The most commonly assessed DSC parameter is relative cerebral blood volume (rCBV), which is increased in tumors secondary to microvascular density and slow flowing collateral vessels. The cut off for differentiating tumor from non-tumor treatment related changes is without an international consensus. One meta-analysis reported $\mathrm{rCBV}$ ratio thresholds ranging from 1.49 to 3.10 [8]. In general, an rCBV ratio of greater than 2 favors either high-grade tumor or tumor progression over treatment-related change [9]. DSC limitations include poor spatial resolution, susceptibility artifact, and $\mathrm{rCBV}$ measurements influenced by blood-brain barrier disruption, as contrast is assumed to remain in the intravascular space [10,11]. Multiple meta-analyses have demonstrated high accuracy $(>90 \%)$ of DSC in delineating tumor recurrence from radiation necrosis $[8,12,13]$. DSC identified tumor neoangiogenesis as a biomarker which could discern between low-grade and highgrade gliomas $[14,15]$. In addition, Law et al. demonstrated that DSC helped identify low-grade gliomas that progress 
rapidly or have higher propensity for malignant transformation [16]. In a prospective study, 13 patients were followed with DSC perfusion and tumors that transformed from low-grade to high-grade glioma demonstrated continuous increase in rCBV DSC up to 12 months before contrast enhancement became apparent [17]. In a multicenter phase II trial of bevacizumab with irinotecan or temozolomide, patients were imaged with DSC and $\mathrm{rCBV}$ values recorded at 2, 8, and 16 weeks after treatment initiation [18]. An early decrease in rCBV was predictive of improved survival when recurrent GBM was treated with bevacizumab. DSC further dissociated between isocitrate dehydrogenase (IDH) wild-type and mutant gliomas [19] and characterized additional molecular and genomic profiles along with textural analysis [20].

DCE MRI utilizes the T1 relaxivity of gadolinium contrast, which is superior to DSC in the presence of hemorrhage. DCE perfusion generates quantitative parameters within a single volume of interest (VOI), including volumetric transfer constant (kTrans), fractional plasma volume $(\mathrm{Vp})$, fractional volume of the extravascular extracellular space (Ve), and semi-quantitative parameters such as area under the curve (AUC). Although DCE has the potential to overcome certain shortcomings of DSC, the technique is less well studied than DSC, is used less frequently in clinical practice, and calculations rely heavily on model dependent approximations $[21,22]$. Despite these challenges, DCE is effective in distinguishing between tumor recurrence and post-treatment changes, in particular radiation necrosis [8, 13]. For instance, in 79 patients with new or increasing contrast enhancing lesions following chemo-radiation, DCE distinguished pseudoprogression from true progression with a sensitivity of approximately $89 \%$ and specificity of $80 \%$ [23]. Despite the strengths and potential uses, further standardization is needed before DSC and DCE can be considered a viable strategy across institutions.

ASL is performed using a radiofrequency pulse which labels endogenous water molecules in blood vessels, which can subsequently be measured as signal reduction as they pass through the tissue of interest. Use of ASL is compromised by signal-to-noise ratio, but has still been shown to identify recurrent disease from radiation necrosis [24]. ASL is also advantageous, as no exogenous contrast is needed. The technique may continue to improve with increasing magnet strengths but currently is used much less frequently than DSC or DCE [24, 25].

\section{MR Spectroscopy}

MRS is an analytical method used to non-invasively assess for water-soluble brain metabolites according to their precession frequency. Since MR induces a characteristic magnetic field in nuclei of differing number of electrons, these various signature resonant frequencies can be detected and analyzed. The chemical species frequently assessed on MRS include creatinine (Cr), N-acetyl aspartate (NAA), choline (Cho), lactate, lipids, alanine, glutamine, glutamate, 2-hydroxyglutarate, citrate, and myoinositol. The $\mathrm{Cr}$ peak is utilized as an internal reference standard relative to other peaks since its level remains high and is relatively comparable across different brain tissue types [26]. Choline is a marker of cell proliferation given its presence in the cell membrane [27, 28]. NAA is found exclusively in neurons and can define cell density and cell viability, [29-31]. Other metabolites can measure tumor metabolism (glucose) and necrosis (lactate or lipids) [32]. Lactate is a marker of anaerobic glycolysis and may represent hypoxic adaptation in higher grade tumor tissue [33]. Myoinositol is a marker of gliosis which can be increased in low-grade gliomas [34, 35]. 2HG is an oncometabolite that is an important biomarker for glioma with IDH mutations, and it can predict tumor grade, tumor progression and the likelihood of treatment response [36].

The standard MRS technique options include single or multi-voxel analysis. With single voxel spectroscopy (SVS), the average metabolite concentration is measured across the volume of a chosen region of interest. SVS at $3 \mathrm{~T}$ with good B0 homogeneity should provide diagnostic quality spectra from tissue volumes down to $4 \mathrm{~cm}^{3}$ over a 5-min acquisition time [37]. Advantages of single voxel MRS are ease of use, shorter scan time, greater field homogeneity, and higher signal to noise ratio compared to multi-voxel spectroscopic imaging. The drawbacks of single voxel spectroscopy include lower spatial resolution across a larger component of tissue, fixed grid placement, and subjective variability of VOI placement. The multi-voxel technique overcomes limitations of single voxel spectroscopy by providing a grid of multiple voxels over a larger region of interest and flexibility of voxel repositioning during post-processing. A multi-voxel spectrographic (MVS) acquisition using a $16 \times 16$ grid of spectra at $3 \mathrm{~T}$ with $1.5 \mathrm{~cm}^{3}$ voxel resolution at TR $1500 \mathrm{~ms}$, an average of one phase encoding step, and elliptical $k$-space sampling may be acquired over an approximately 5-min time period [37]. MVS imaging suffers from lower signal-to-noise ratio and crossvoxel signal contamination which impedes precision of quantitation. Additional concerns regarding MRS in general are lack of standardization of imaging acquisition, differences in magnet strength, and artifact induced by either the presence of blood hemosiderin within a tumor or marrow lipid within the calvarium for more peripheral lesions [38]. To overcome inherent limitations of both single and multi-voxel spectroscopy, other techniques are being developed. For instance, $\mathrm{Li}$ et al. developed an innovative super-resolution whole brain three-dimensional spectroscopy technique to visualize $2 \mathrm{HG}$ which had resolution equal to the best single voxel spectroscopy $\left(0.32 \mathrm{~cm}^{2}\right)$ [39]. The technique also would eliminate operator dependence and detect potential tumor regions outside of standard two-dimensional spectroscopic regions of 
interest. The main drawback to this technique was long scan times of greater than 18 min for a single acquisition.

MRS was reported to have high accuracy (92\%) for differentiating neoplastic from non-neoplastic tissue and was improved when combination with other advanced MR imaging such as PWI (96\%) [40]. Various studies since have also shown similar accuracy $[13,41,42]$, but a meta-analysis indicated that MRS may have more benefit when combined with other advanced imaging modalities rather than interpreting the results with MRS alone [43]. The benefit of combining various imaging modalities has been recommended in more recent papers as well [44-46]. Higher Cho and lower NAA with increased lactate are more consistent with glioma rather than metastases or central nervous system lymphoma [47, 48]. Although there is no standardized numerical cutoff value for these metabolites, a Cho/NAA of 2.2 is proposed as a reasonable cutoff [38]. For glioma grading, MRS was better than conventional imaging alone [49]. Using Cho/NAA and Cho/ $\mathrm{Cr}$ ratios, an accuracy of 80-97\% was achieved in distinguishing tumor progression from radiation necrosis $[50,51]$. The most heralded use of MRS in the presence of a known malignant brain tumor has been for distinguishing progression of tumor from treatment related MRI changes (i.e., pseudoprogression). However, in reality, differentiating these two entities remains highly challenging since both processes can present with low NAA from neuronal loss and dysfunction, high Cho from abnormal cellular membrane attenuation/ integrity, and high lactate and lipids from anaerobic metabolism [52].

\section{MR Diffusion-weighted Imaging}

Along with its routine clinical role, DWI provides important functional and physiological information about brain tumors and the peri-tumoral microenvironment. Direct measurement of water mobility becomes an imaging biomarker of tissue pathology, as its movement is dependent on factors such as viscosity, cellularity, and the tortuosity of the extracellular space [32]. The ADC sequence provides quantitative data derived by measuring restriction of water molecules at differing degrees of diffusion weighting (i.e., $b=0,500,1000$, or even $3000 \mathrm{~s} / \mathrm{mm} 2$ ). At least two different $b$ values are required, and the ADC value for each voxel is calculated using linear regression. Restriction of water diffusion secondary to tumor cellularity results in hypointense or low ADC values, useful for differentiating tumor type and grade [53, 54]. For instance, the degree of ADC hypointensity will typically be greater in lymphoma, a highly cellular tumor, as compared to high-grade glioma or metastases. Similarly, non-necrotic high-grade glioma and metastases will have greater reduction in ADC values than low-grade malignancies. Edema associated with highgrade tumors limits ADC sensitivity, as it increases the average ADC intensity [32].
DWI can also be useful for treatment response and differentiating chemo-radiation-induced changes from tumor given lower ADC signal of tumor [55]. Restricted diffusion in the postsurgical setting helps identify cytotoxic edema. The associated parenchyma can enhance in the subacute setting and could be confused with tumor progression. Accordingly, baseline MRI is recommended within $48 \mathrm{~h}$ of surgery [56]. DWI has been shown to predict prognosis within three weeks of therapy initiation $[57,58]$ and was also predictive of treatment response to bevacizumab [59-61]. For treated GBM, progression of disease typically demonstrates lower ADC values compared with pseudoprogression. A meta-analysis demonstrated moderate accuracy using ADC to delineate progression of GBM from radiation necrosis with a pooled sensitivity of $71-82 \%$ and sensitivity of $84-87 \%[13,62]$. The proposed ADC threshold for disease progression in GBM is $1.3 \times$ $10^{-3} \mathrm{~s} / \mathrm{mm}^{2}[41,63]$.

Standard DWI acquisition suffers from the assumption that water diffusion occurs in the absence of boundaries via a uniform Gaussian distribution. In reality, the structure of cell membranes, intracellular organelles, and water compartments in cerebral tissues make this assumption inaccurate [64]. Therefore, more sophisticated models of quantitative DWI have been developed, such as diffusion tensor imaging (DTI) [65]. In DTI imaging, the application of a diffusion tensor model onto DWI data determines diffusion along each of three axes of a given voxel and produces a threedimensional ellipsoid, known as the diffusion tensor. The diffusion tensor provides more complete anisotropic and structural data of each voxel, yielding fractional anisotropy images which clearly delineate white matter tracts by coding left-right (red), anterior-posterior (green), and superior-inferior (blue) diffusion. Diffusion kurtosis imaging (DKI) extends the principles of DTI even further to quantify the deviation from a Gaussian distribution to create a more accurate model [66, 67]. By acquiring data in more than 15 nonlinear directions, both kurtosis metrics (mean, axial, and radial kurtosis) and conventional diffusion metrics (mean, axial, radial diffusivity, and fractional anisotropy) are obtained. Meta-analyses that examined the diagnostic accuracy of DKI for differentiating high- and low-grade gliomas projected a pooled area under the curve of 0.94 and 0.96 for mean kurtosis [68, 69]. More recently, Abdalla et al. performed an extended and updated meta-analysis and also concluded that DKI has good diagnostic accuracy in differentiating high- from low-grade gliomas [70]. Accuracy was consistent across different studies with varied acquisition and post-processing techniques, indicating DKI may be useful across different institutions and populations given greater optimization and standardization. Additional promising advanced DTI techniques include intravoxel incoherent motion (IVIM) and neurite orientation and dispersion imaging (NODDI), which utilizes multiband imaging [71]. IVIM allows separate estimates of tissue 
diffusivity and microcapillary perfusion, while NODDI can measure the microstructure of dendrites and axons to provide data on neuronal changes.

\section{MR Chemical Exchange Saturation Transfer}

MR CEST is a non-contrast technique which detects and amplifies metabolic substrates in the tumor tissue not found with other MRI sequences [72-75]. Imaging relies on the exchange between targeted chemical compounds and bulk water [76]. The most frequent CEST utilized for brain tumor imaging is amide proton transfer (APT) also called amide-CEST MRI, which detects and amplifies an exchange between the intrinsic hydrogen protons located on amide groups and water molecules within tissue [77]. The most abundant source of amide groups in tissue are contained on the amino acids of mobile cellular peptides and proteins, which are elevated above background brain in various disease states, including brain tumors [78]. Therefore, amide-CEST MRI derives its signal specificity from an overabundance of cytosolic proteins within GBM cells. In addition to amide groups, hydroxyl and amine groups are also mobile protons that can be used to generate detectable CEST signals (i.e., amine-CEST and hydroxyl-CEST). In comparison to metallic contrast agents (i.e., gadolinium or iron oxide), CEST does not negatively impact the intrinsic MRI properties of tissues nor induces a tissue toxicity potential [76]. Although an advantage of CEST is the reliance on intrinsic contrast within the tissue, exogenous application of solutes such as glucose [79] and glucose derivatives [80] can also be utilized. Largely though, CEST has been developed to take advantage of intrinsic unique properties of peptide and protein detection in the mobile phase. Another CEST technique that has recently been applied to GBM detection is the relayed nuclear Overhauser effect (rNOE), located in the $Z$ spectrum up field from water resonance $(0-5 \mathrm{ppm})[81,82]$. Both APT and rNOE signals are associated primarily with protein and peptide presence, although rNOE may be more associated with protein size and configuration [83, 84]. Therefore, it is likely that APT and rNOE provide different but similarly valuable information holding promise as individual imaging biomarkers for different tumor properties. Since the discovery and improvement of CEST, the technique has been applied to human imaging in a complementary manner to other MRI methods, particularly with regard to differentiating infiltration of tumor compared with peri-tumoral edema [85, 86]. In the clinical setting, amide-CEST MRI demonstrated an ability to delineate low- from high-grade gliomas [87-89], differentiate tumor from treatment-related changes including pseudoprogression [90, 91], predict treatment response of brain metastases following radiation [92], and provide early (2-week) imaging biomarker evidence of GBM response to chemo-radiation therapy [93]. Finally, amide-CEST MRI has potential for identifying IDH mutation status in low-grade tumors as well as MGMT methylation status in high-grade tumors [94, 95].

\section{MR Functional Magnetic Resonance Imaging and Diffusion Tensor Imaging}

While previously discussed advanced MRI techniques provide valuable anatomic, molecular and chemical information, functional MRI (fMRI), and DTI are readily available cortical and white matter mapping techniques which provide valuable information on brain activity adjacent to brain tumors. Blood oxygen level-dependent (BOLD) fMRI relies on the paramagnetic properties of oxyhemoglobin, which is increased relative to deoxyhemoglobin in the activated regions of the brain during either task-based or resting-state acquisition. Task-based fMRI can be tailored to specific motor and language functions prescribed to delineate eloquent cortices in relation to tumor location. Resting-state fMRI evaluates neural networks at rest and can be a useful adjunct in cognitively impaired patients, especially for language mapping [96, 97]. fMRI results must be interpreted with caution, as they can be limited by susceptibility, respiration, medications, motion, task uniformity, tumor vascularity leading to neurovascular uncoupling, and patient cooperation [98-100]. In one study, clinicians anecdotally reported a $30 \%$ discrepancy between fMRI results and direct cortical stimulation mapping at surgery, although fMRI can map beyond the surgically exposed gyri [101]. DTI uses anisotropic diffusion properties of axonal water to delineate white matter tracts such that their relationship with the planned approach and resection can be identified. A 1-cm margin of safety from critical structures has been proposed and utilized $[102,103]$. When employed in conjunction with other advanced MRI techniques, fMRI and DTI can help preserve eloquent regions of the brain while maximizing high-grade tumor resection volume.

\section{Positron Emission Tomography}

PET imaging relies on detection of emitted photons from intravenously delivered positron emitting radiotracers to provide dynamic functional molecular imaging. Depending on the molecule the radionuclide is bound to, biological processes such as glucose consumption and amino acid/analogue uptake can be visualized non-invasively and quantitatively. A PET scanner detects emitted pairs of $511 \mathrm{keV}$ photons through annihilation coincidence detection to obtain projections of radioactivity distribution in the patient. Most PET systems are coupled to CT scanners, although MRI coupled systems are increasing in number and are more optimal for brain tumor imaging. Typically, brain tumor PET results are based on standard uptake value (SUV) and reported as a mean and maximum tumor to brain ratio (TBR). Certain radiotracers reveal additional dynamic 
information through the study of radiotracer uptake and release characteristics, including time to peak and slope of the curve. Advantages of PET include high quantitation and sensitivity and the ability to co-register with other imaging modalities. Limitations of PET include lower spatial resolution, radiation exposure, and relatively high cost with complex equipment. While there are many new and experimental PET radiotracers in development, clinically available PET radiotracers for brain tumor imaging are comprised of mostly ${ }^{18} \mathrm{~F}$-fluorodeoxyglucose (FDG) and amino acid radiotracers, which include FET, ${ }^{11} \mathrm{C}$ methylmethionine (MET), and 3,4-dihydroxy- $6-{ }^{18} \mathrm{~F}$-fluoro-Lphenylalanine (FDOPA).

\section{Fluorodeoxyglucose PET}

The wide availability and low cost of FDG has led to many published studies in brain tumor imaging, although high physiologic background uptake is a significant limitation [104, 105]. Technique modifications have attempted to offset the difficulty of FDG to delineate tumor borders and overcome nonspecific uptake in other processes such as with inflammation. Multiphase FDG PET/CT was recently used in the evaluation of high-grade gliomas and metastatic lesions [106]. Normal brain FDG activity decreases slightly over time, while activity in malignant tissue remains steady or increases. This difference was exploited by fusing dual-phase CT with MRI. Others have combined FDG PET/CT with MR perfusion. In a prospective study, FDG and DCE were both useful in distinguishing between progression and radiation injury, although DCE slightly outperformed FDG [107]. ASL perfusion, DSC perfusion, and FDG PET/CT were studied in 30 patients with grades II-IV glioma previously treated with surgery and proton beam therapy for the ability of each modality to distinguish progression of disease from radiation necrosis [108]. In regions with mixed radiation necrosis, ASL was considered superior to DSC and FDG for detecting tumor recurrence.

Despite the limitations of using FDG in brain tumor detection, hybrid FDG PET/MRI appears to improve diagnosis. Hojjati et al. compared hybrid FDG PET/MRI and FDG $\mathrm{PET} / \mathrm{CT}$ in 19 patients who underwent both exams in a single day [109]. Using a TBR mean of greater than 1.31, FDG PET/ MRI was superior to FDG PET/CT with an AUC of 0.94. In another hybrid FDG PET/MRI study, 35 glioma patients with 41 lesions were assessed with suspected tumor progression or treatment-induced necrosis [110]. Individual parameters which achieved significance include rCBV mean (77.5\%), ADC mean (78.0\%), Cho/Cr (90.9\%), TBR max (87.8\%), and TBR mean $(87.8 \%)$. When all three MR imaging parameters were combined, the AUC improved to 0.913. Similarly, hybrid PET/MRI was performed in 41 patients with highgrade glioma to compare FDG performance to DCE perfusion metrics [111]. FDG had lower specificity than DCE (56\% vs. $89 \%)$, but the overall accuracy was similar $(80 \%$ vs. $83 \%)$.
Fig. 1 Hybrid FET PET/MRI imaging. Representative images of a WHO grade IV GBM with a lesion progressively enlarging at 6 months following surgery and radiation therapy. Top left to bottom right include FLAIR, DCE Ktrans, DSC rCBV, T1 post-contrast, FET PET, and fused hybrid FET PET/MRI images. Both DCE and DSC images show abnormal perfusion corresponding to areas of abnormal enhancement indicating increased vascularity. The bottom middle image shows abnormally elevated FET PET signal in a pattern consistent with the MRI perfusion findings. Subsequent surgical resection confirmed tumor recurrence on histopathology. TBR max was 3.74 and TBR mean was 3.13. The dynamic characteristics of the FET uptake can also be studied in a region of interest over time as shown on the time activity curve ( $Y$ axis $=$ absolute SUV, $X$ axis $=$ time in seconds). In this case, a 45-min acquisition occurred. The slope of the curve was 3.60. A downward slope at the second half of the acquisition is suggestive of presence of tumor, while an upward slope has been reported to be more indicative of treatment related change such as pseudoprogression. Data was generated in QImage Softwared, NIH NCI 5R01CA202695. Images were de-identified and approved under an institutional IRB protocol.

There was up to $27 \%$ discordance between FDG and DCE. Pyatigorskaya et al. assessed the potential for FDG PET/MRI to overcome limitations of separately performed MRI and FDG PET to differentiate between recurrence of high-grade glioma compared with radionecrosis [112]. Combined PET/ MRI analysis differentiated between recurrence and radionecrosis with improved diagnostic accuracy (95\% vs. $63 \%$ for PET alone and $82 \%$ for MRI alone). FDG being a reliable, cost-saving radiotracer, combined FDG PET/MRI could still play a role in the follow-up of high-grade brain tumors where amino acid PET is not available.

\section{Amino Acid PET with an Emphasis on FET PET}

To help address critical shortcomings of MRI and FDG PET, international working groups recommend amino acid PET imaging in conjunction with MRI for assessment of primary high-grade malignant brain gliomas [104] [113] and for brain metastases [105]. Amino acid PET is recommended for discerning neoplastic from non-neoplastic processes, delineation of tumor extent for resection or re-resection planning, hot spot localization for biopsy planning, prognostication, postresection assessment, radiation therapy planning, baseline monitoring for chemo-radiation, diagnosis of treatmentrelated changes versus progression/recurrence, and baseline imaging for adjuvant treatment monitoring [104]. Numerous studies have been published on MET, FET, and FDOPA that substantiate these recommendations, and have been reviewed extensively, for instance by Werner et al. [114], Stegmayr et al. [115] and Lohmann et al. [116]. Although a promising amino acid agent, MET suffers from a short half-life (20 min compared with 110 min for FET and FDOPA), making production possible only in centers with a cyclotron $[117,118]$. The advantages of F18 labeling and extensive clinical results for FET have largely replaced short lived radiotracers in many 


\section{MR FLAIR}

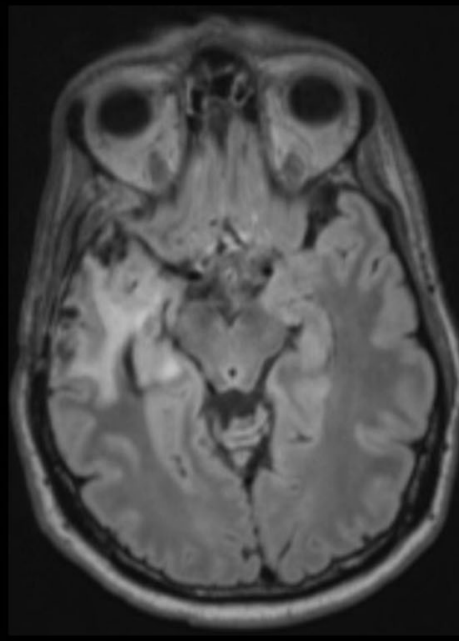

MR T1 Post-Con

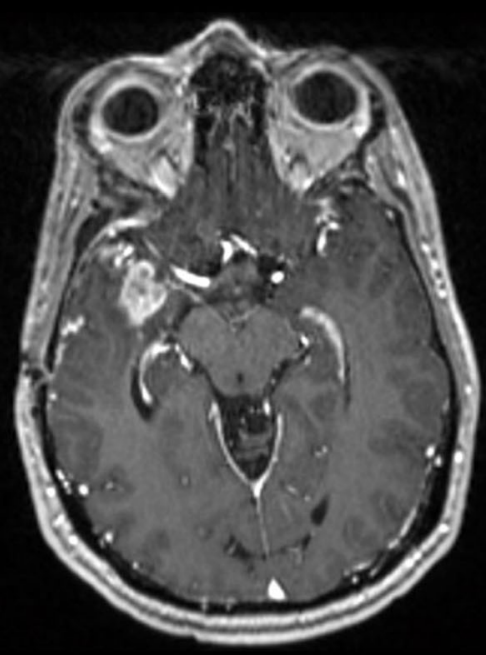

MR DCE Ktrans

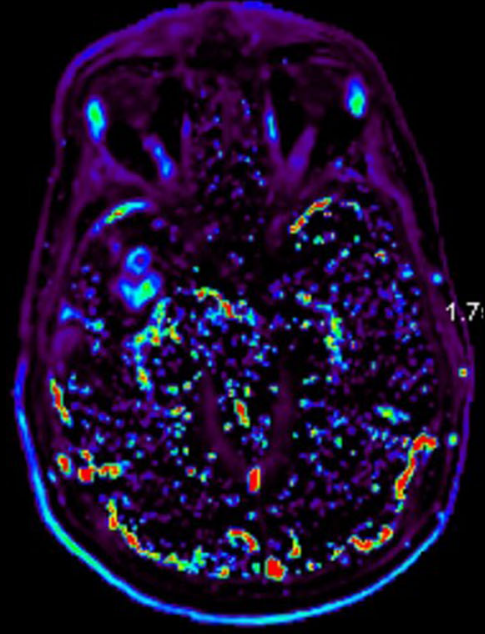

FET PET

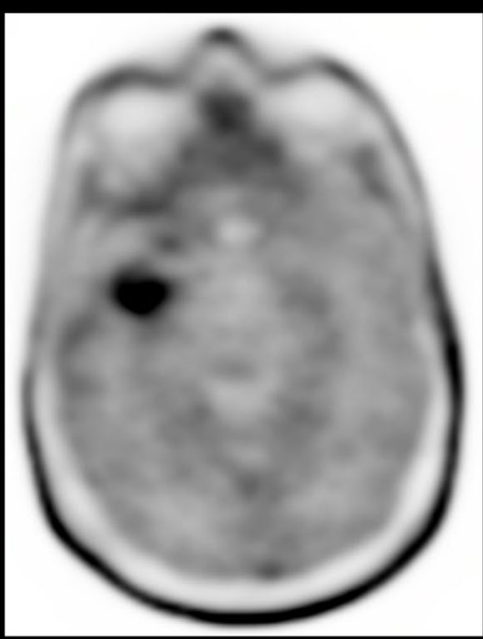

MR DSC rCBV

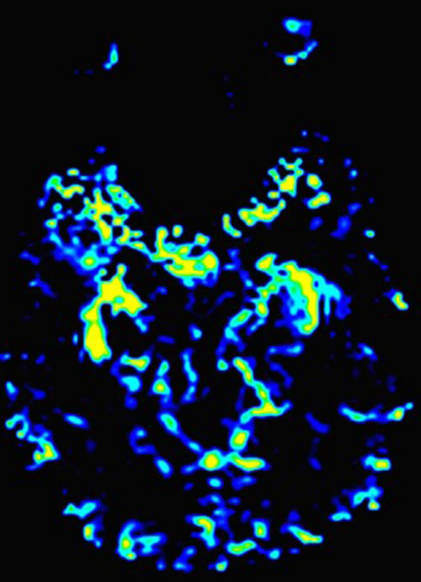

FET PET/MR Fusion

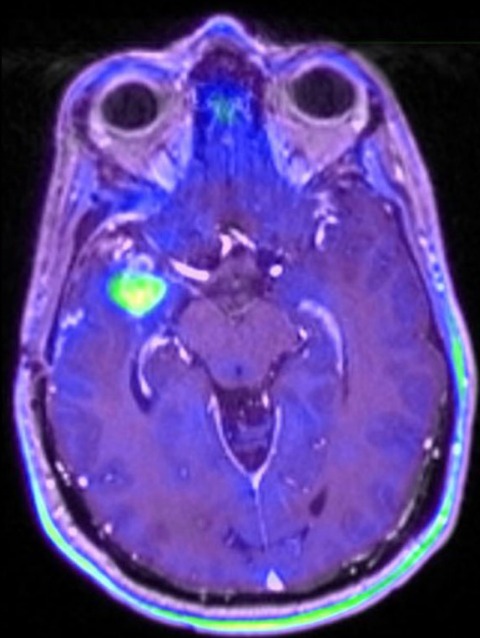

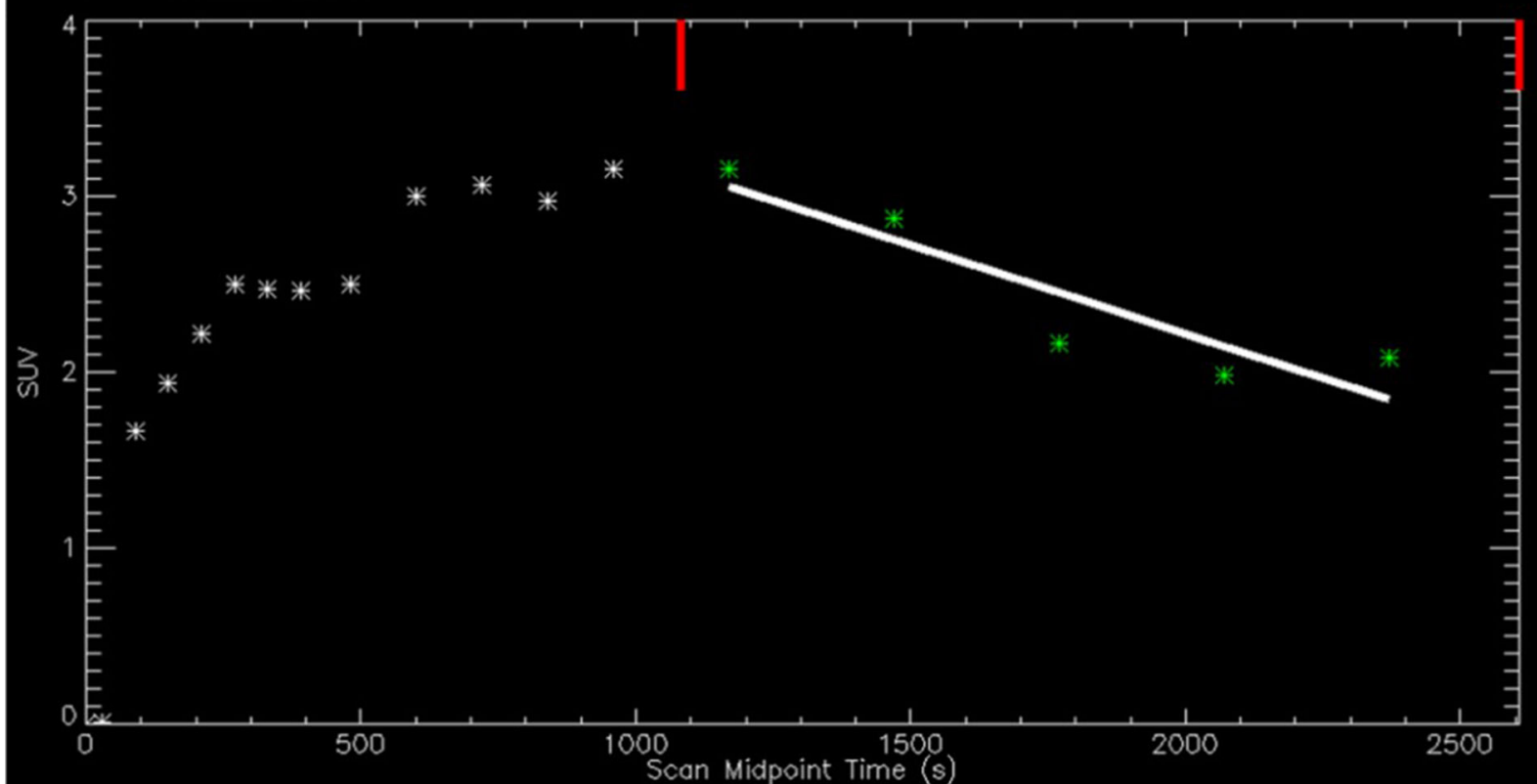


centers across western Europe, including MET [115]. For instance, using static and dynamic FET PET and conventional MRI, delineation between pseudoprogression and tumor progression has an accuracy of $96 \%$ (sensitivity $100 \%$ and specificity $91 \%$ ) [119]. FDOPA is also a promising amino acid PET agent, but there is not nearly as much published data in comparison to FET, which has been used safely in humans since 1999. Using FDOPA it is also difficult to distinguish tumor involving the nigrostriatal structures as there is intrinsic physiologic uptake of the radiotracer in this region. The cost effectiveness of amino acid PET in Europe has also been demonstrated for differentiating recurrent brain metastasis from radiation induced enhancement [120].

FET is a synthetic amino acid derived from tyrosine, and just like tyrosine, is passively taken into cells via the system $\mathrm{L}$ transporter (LAT) in exchange for leucine [121]. LAT1 and LAT2 are over expressed on the membrane of tumor cells, secondary to a need for amino acids for manufacturing protein [122]. The LAT receptors were also overexpressed in brain tumor cells undergoing rapid cell proliferation and in tumor angiogenesis [123]. Once inside the cell, FET is not associated with a known efflux transporter and is otherwise not metabolized further [121]. Therefore, the retention time in pathologic tumor tissue is higher than for other natural amino acid radiotracers. Although static amino acid PET parameters such as TBR max and mean have high diagnostic accuracy alone, addition of dynamic FET PET imaging may contribute to increased confidence of diagnosis. Unpublished imaging at our institution shown in Fig. 1 mirrors characteristic dynamic FET features [124-126] with more rapid tracer uptake into higher grade tumor tissue (early upslope) and subsequent wash-out (late downslope).

Combination of individually acquired FET PET with MR PWI in assessment of high-grade glioma has shown promise for determining glioma extent and grading and assessing tumor progression from pseudoprogression. FET PET also exhibits high diagnostic accuracy in differentiating radiation injury from tumor progression in patients with brain metastases [124, 127, 128]. Recurrence prediction for GBM was assessed with FET PET/CT and compared with FDG PET/CT in 16 patients who also underwent DWI and DCE perfusion [129]. While FDG, FET, and PWI correlated in both contrast enhancing and noncontrast enhancing tissue that progressed, FET proved to be the most important parameter for predicting recurrence based on standardized coefficients for recurrence models.

Individual FET PET subsequently combined with MRS exhibit improved sensitivity and specificity when used in a complimentary manner versus either modality alone [130-132]. Both FET PET and MRS were employed in 50 patients with newly diagnosed suspected diffuse gliomas (167). Both FET $\mathrm{TBR}$ and NAA/Cho ratio were independently predictive of histologic identification of tumor tissue. While MRS had higher sensitivity, FET TBR exhibited higher specificity. When both
FET PET and MRS were positive, an accurate diagnosis of tumor was determined in $97 \%$ of patients as validated histologically. An emerging theme is spatial incongruence between MRS and PET. In a study by Mauler et al., PET and MRS were incongruent based on their respective mean center of the mass by $9 \pm 8 \mathrm{~mm}$ [133]. In another a study to assess spatial congruence between FET PET and MRS, TBR was compared to concentrations of Cho, $\mathrm{Cr}$, and total NAA in 15 patients with grades II-IV gliomas [134]. Only an elevated Cho/NAA ratio correlated with strong or moderate elevation in FET TBR.

FET PET/CT has also been assessed against DWI and CEST. Data from initial studies revealed incongruent results, suggesting FET, DWI, and CEST evaluate different biologic processes and information in brain tumors $[135,136]$. However, a more recent study from 2020 utilized FET PETMRI combined with amide-CEST and DSC perfusion to generate intra-lesional hot spot volumes (HSV) in 46 glioma patients [137]. HSVs generated with amide-CEST in GBM patients were larger than for FET or DSC HSVs. Amide-CEST HSVs were lower in patients with low-grade gliomas compared with GBM patients. In addition, there was a high correlation of the HSVs for amide-CEST and FET regions. When compared with tissue from targeted biopsies in 10 GBM patients, both amide-CEST and FET correlated significantly with cellularity while tissue vascularity correlated with CBV and FET.

\section{Hybrid FET PET/MRI}

Of all studies to date on hybrid PET/MRI, FET has been utilized the most, further confirming its utility in brain tumor imaging. In a study by Filss et al., hybrid FET PET/MRI was performed to compare FET TBR with DSC rCBV values in 56 patients with gliomas, including 24 patients with GBM [138]. The most important finding was that tumor volumes were significantly larger using FET TBR maps compared to rCBV maps. Spatial overlap of both imaging parameters was poor with a congruence of only $11 \%$. FET could clearly separate tumor from background more definitively than when using rCBV perfusion maps. The mean distance between the local hot spots also differed considerably by $25.4 \pm 16.1 \mathrm{~mm}$. The authors concluded that FET and rCBV yield different biological information. In another hybrid FET PET/MRI study, FET parameters were compared with DSC perfusion in 32 patients with gliomas [139]. Although quantitative tumor volumes were correlated, there was persistent spatial incongruence in the assessed mixed population of glioma patients. However, simultaneous assessment of tumor using both FET PET and DSC perfusion offers complementary information of imaging biomarkers, specifically tumor vascularity and tumor metabolism. In cases where susceptibility abnormality from prior hemorrhage or surgery precludes assessment of certain regions on DSC perfusion, other sequences including FET PET can overcome this limitation. 
Gottler et al. also employed hybrid FET PET/MRI in the clinical work-up of glioma patients to study the inter- and intra-lesional variability of static and dynamic FET compared with DSC blood volumetric perfusion parameters [126]. The FET TBR uptake was significantly higher than rCBV and the location of hotspots differed considerably. There was, however, a significant correlation between peak values of rCBV and static FET TBR across all patients. In addition, clear intra-lesional spatial correlation was found between the dynamic FET parameters and rCBV. Additional evidence was presented in favor of multimodal, multiparametric imaging in the management of glioma patients, where both perfusion and FET uptake provide different, yet equally important information regarding tumor biology.

Thirty-two glioma patients underwent hybrid FET PET/ MRI with DSC perfusion to address the question of radiation necrosis compared with tumor progression [140]. Multiple parameters were assessed, and again the complimentary nature of FET PET combined with MRI in the same session was reproducible with synergetic effects. When assessed individually, the accuracy of TBR max (94.1\%), TBR mean (88.2\%), ADC mean (80.4\%), Cho:Cr ratio (96.4\%), normalized rCBV $(89.9 \%)$ was less than when all parameters were combined $(96.87 \%)$. These studies corroborate the superiority of amino acid PET and point the benefit of hybrid advanced MRI for evaluation of malignant brain tumors. In assessment of glioma recurrence, multiparametric FET PET/MRI with dynamic FET parameters again yielded the highest diagnostic accuracy of any individual modality [141].

Hybrid FET PET/MRI was utilized to compare regional tumor FET uptake versus Cho/NAA on MRS in 41 patients [133]. The volume of elevated Cho/NAA ratio was compared with FET volumes, which revealed abnormal FET activity and Cho/NAA characteristics are not always congruent regionally within same tumor tissue and differ in their center of mass by 9 $\pm 8 \mathrm{~mm}$. None of the parameters used in the study correlated with tumor grade. However, hybrid PET/MRI was employed to compare FET TBR and $\mathrm{rCBV}$ DSC perfusion to grade newly diagnosed, untreated glioma in 72 patients [142]. The diagnostic accuracy of FET PET and PWI to discriminate LGG from HGG was similar with highest area under the curve (AUC) values for TBR mean and TBR max. In cases that had increased tumor signal with both methods, local hotspots were incongruent in $78 \%$ with a mean distance of $10.6 \pm 9.5 \mathrm{~mm}$. Consistent incongruence within the hotspots provides further evidence of complementary tumoral information from each modality. This same group of investigators found that FET PET was superior to DSC rCBV perfusion for detecting progressive or recurrent glioma (76\% vs. 52\%) [143]. FET TBR max was the only parameter to discriminate treatment-related changes from progressive or recurrent gliomas with an accuracy of $81 \%$. Spatial incongruence between FET and DSC was up to $75 \%$ within intra-lesional hotspots, which was confirmed in $80 \%$ of the cases with tissue samples.

In a single center study, hybrid FET PET/MRI was used for 26 patients to assess GBM recurrence versus radiation necrosis [46]. Multiparametric, multimodality assessment yielded an accuracy of $93.8 \%$ for FET TBR max, $87.5 \%$ for FET TBR mean, 90.6\% for normalized rCBV mean, $96.9 \%$ for MRS Cho/Cr ratio, and $81.3 \%$ for ADC mean. Accuracy of both normalized rCBV mean and ADC mean was improved when combined with FET TBR max or MRS Cho/Cr ratio. TBR max or TBR mean with $\mathrm{Cho} / \mathrm{Cr}$ ratio yielded the greatest accuracy, approaching $97 \%$. The maximum area under the curve was achieved when combining FET TBR mean, DSC rCBV, and MRS Cho/Cr ratio values. Hybrid FET PET/MRI was also utilized to assess for glioma recurrence in 63 lesions suggestive of recurrence in 47 glioma patients in a retrospective analysis [141]. Diagnosis was based on histology in 23 cases and follow-up imaging in 40 cases. Combination of all multiparametric multimodality parameters was superior to any one individual assessment including static PET, dynamic PET, PWI, or DWI. In another study, 32 glioma patients underwent hybrid FET PET/MRI with DSC perfusion to address the question of radiation necrosis compared with tumor progression [140]. Multiple parameters were assessed and again the complimentary nature of FET PET combined with MRI in the same session was reproducible with synergetic effects.

Increasing attention is being given to the assessment of nonenhancing tumor regions [144], highlighting the need for modalities to reliably distinguish between edema, gliosis, and tumor [113]. There is early compelling prognostic data on widening resection margins beyond contrast enhancement to include non-enhancing mass-like signal abnormality in suspected high-grade gliomas [145]. These early findings suggest that advanced imaging modalities which accurately detect nonenhancing tumor will be of growing value. Hybrid FET PET/ MRI was utilized to demonstrate that FET metabolic activity significantly exceeds tumor volume compared with MRI contrast enhancing regions with tumor confirmed using stereotactic biopsy [146]. These results were similar to Lohmann et al. who performed FET PET and conventional MRI to show that 43 out of 50 patients $(86 \%)$ had FET tumor volumes that were significantly larger than contrast-enhanced volumes [147].

A growing body of evidence favoring the use of FET, its extensive safety profile and benefits of PET/MRI in brain tumor imaging leave little reason to exclude this agent as standard of care for brain tumor diagnosis and management.

\section{Radiogenomics, Radiomics, and Machine Learning}

While the previously discussed advanced and complementary imaging modalities provide critical information, this section 
seeks to address the abundance of data available in imaging beyond what may be visually apparent. Radiomics is an emerging area of translational research associating qualitative and quantitative data from clinical imaging with tissue histopathology, with the goal of affecting clinical management and predicting outcomes. The term radiogenomics applies when these imaging features are associated with genetic changes. Machine learning describes the study and implementation of computer algorithms that automatically improve at a defined task with experience. Deep learning is a subset of machine learning applied through large and multilayered artificial neural networks inspired by the human brain. Given the complexity and large data sets that clinical imaging provides, which may not always be appreciable to the human eye, machine learning is often used as a primary tool in radiomics [148]. These methods provide future pathways and opportunities for highly accurate, non-invasive diagnostic, and prognostic data.

Either IDH1 or IDH2 mutations are a defining classification for adult gliomas, with vast majority of gliomas as IDH1 mutations. IDH1/2 mutant tumors generally having longer progression-free survival and overall survival whether in low-grade glial tumors compared to high-grade GBM. In addition, IDH mutation with chromosome $1 \mathrm{p}$ and $19 \mathrm{q}$ codeletion is the molecular signature for oligodendroglioma, all but removing oligoastrocytoma as a histopathologic diagnosis [149]. In addition, epigenetic differences such as O6methylguanine-DNA methyltransferase (MGMT) promoter methylation in GBM have shown improved response to combination of temozolomide and radiation therapy versus radiation therapy alone [150]. In addition, both MGMT promoter methylation and IDH mutation are independent factors favoring pseudoprogression over tumor progression in high-grade glioma using standard therapies [151].

In both lower grade gliomas and GBM, multiple textural feature analysis shows a range of $72-95 \%$ predictive accuracy for IDH mutation with T1 contrast enhancement and FLAIR images providing the most discriminating information. The addition of advanced MR sequences such as diffusionweighted images including parameters such as fractional anisotropy and diffusion kurtosis as well as DSC perfusion have increased accuracy. Finally, using deep learning methods, IDH mutation accuracy prediction is similar to textural feature analysis at $85-97 \%$ with the advantage of bypassing the timeconsuming step of post-processing textural radiomic features. $1 \mathrm{p} / 19 \mathrm{q}$ co-deletion accuracy was $92 \%$ and MGMT yielded $61-83 \%$ accuracy $[152,153]$.

Recent studies have also included FET PET/MRI hybrid in predicting IDH mutation with $93 \%$ accuracy when combining standard parametric data from FET PET combined from textural analysis [154]. In another study combining FET PET and MR fingerprinting, a technique quantifying T1- and T2weighted MR images, Haubold et al. used machine learning to analyze these combined techniques for glioma mutation.
They were able to find area under the curve measurements of $75.7 \%$ for MGMT promoter methylation, $88.7 \%$ IDH mutation, and $97.8 \%$ for $1 \mathrm{p} 19 \mathrm{q}$ co-deletion [155].

\section{Conclusion}

Developments in advanced neuroimaging are providing new avenues for detection of recurrent disease and delineation of healthy brain tissue from malignant tissue. Advanced MRI techniques are more effective at identifying disease involved tissue in comparison to traditional MRI, but still have limitations. Hybrid PET/MRI, in particular, FET PET, is increasingly being recognized as a highly accurate method that can improve patient outcomes when used for pre-operative planning and post-treatment monitoring. Radiomics and radiogenomics utilize clinicopathologic, genetic, and imaging data to produce accurate non-invasive diagnostic and prognostic information. Utilization of advanced MRI, hybrid PET/MRI, and radiomics present a considerable opportunity to improve patient outcomes in the field of neuro-oncology.

\section{Declarations}

Conflict of Interest None of the authors has any potential conflicts of interest to disclose.

Human and Animal Rights and Informed Consent This article does not contain any studies with human or animal subjects performed by any of the authors.

Open Access This article is licensed under a Creative Commons Attribution 4.0 International License, which permits use, sharing, adaptation, distribution and reproduction in any medium or format, as long as you give appropriate credit to the original author(s) and the source, provide a link to the Creative Commons licence, and indicate if changes were made. The images or other third party material in this article are included in the article's Creative Commons licence, unless indicated otherwise in a credit line to the material. If material is not included in the article's Creative Commons licence and your intended use is not permitted by statutory regulation or exceeds the permitted use, you will need to obtain permission directly from the copyright holder. To view a copy of this licence, visit http://creativecommons.org/licenses/by/4.0/.

\section{References}

1. Wirsching HG, Galanis E, Weller M. Glioblastoma. Handb Clin Neurol. 2016;134:381-97.

2. Delattre JY. Improving diagnosis and management of primary brain tumors. Curr Opin Neurol. 2017;30(6):639-42.

3. McFaline-Figueroa JR, Lee EQ. Brain Tumors. Am J Med. 2018;131(8):874-82.

4. Stupp R, Taillibert S, Kanner AA, Kesari S, Steinberg DM, Toms $\mathrm{SA}$, et al. maintenance therapy with tumor-treating fields plus temozolomide vs temozolomide alone for glioblastoma: a randomized clinical trial. Jama. 2015;314(23):2535-43. 
5. Ostrom QT, Patil N, Cioffi G, Waite K, Kruchko C, BarnholtzSloan JS. CBTRUS Statistical report: primary brain and other central nervous system tumors diagnosed in the United States in 2013-2017. Neuro-Oncology. 2020;22(Supplement_1):iv1-iv96.

6. Wen PY, Macdonald DR, Reardon DA, Cloughesy TF, Sorensen AG, Galanis E, et al. Updated response assessment criteria for high-grade gliomas: response assessment in neuro-oncology working group. J Clin Oncol. 2010;28(11):1963-72.

7. Shiroishi MS, Boxerman JL, Pope WB. Physiologic MRI for assessment of response to therapy and prognosis in glioblastoma. Neuro-Oncology. 2016;18(4):467-78.

8. Patel P, Baradaran H, Delgado D, Askin G, Christos P, John Tsiouris A, et al. MR perfusion-weighted imaging in the evaluation of high-grade gliomas after treatment: a systematic review and meta-analysis. Neuro-Oncology. 2017;19(1):118-27.

9. Sawlani V, Patel MD, Davies N, Flintham R, Wesolowski R, Ughratdar I, et al. Multiparametric MRI: practical approach and pictorial review of a useful tool in the evaluation of brain tumours and tumour-like lesions. Insights Imaging. 2020;11(1):84.

10. Jain R. Measurements of tumor vascular leakiness using DCE in brain tumors: clinical applications. NMR Biomed. 2013;26(8):1042-9.

11. Filss CP, Cicone F, Shah NJ, Galldiks N, Langen KJ. Amino acid PET and MR perfusion imaging in brain tumours. Clin Transl Imaging. 2017;5(3):209-23.

12. Hu LS, Baxter LC, Smith KA, Feuerstein BG, Karis JP, Eschbacher JM, et al. Relative cerebral blood volume values to differentiate high-grade glioma recurrence from posttreatment radiation effect: direct correlation between image-guided tissue histopathology and localized dynamic susceptibility-weighted contrast-enhanced perfusion MR imaging measurements. AJNR Am J Neuroradiol. 2009;30(3):552-8.

13. van Dijken BRJ, van Laar PJ, Holtman GA, van der Hoorn A. Diagnostic accuracy of magnetic resonance imaging techniques for treatment response evaluation in patients with high-grade glioma, a systematic review and meta-analysis. Eur Radiol. 2017;27(10):4129-44.

14. Jain R, Gutierrez J, Narang J, Scarpace L, Schultz LR, Lemke N, et al. In vivo correlation of tumor blood volume and permeability with histologic and molecular angiogenic markers in gliomas. AJNR Am J Neuroradiol. 2011;32(2):388-94.

15. Law M, Yang S, Wang H, Babb JS, Johnson G, Cha S, et al. Glioma grading: sensitivity, specificity, and predictive values of perfusion MR imaging and proton MR spectroscopic imaging compared with conventional MR imaging. AJNR Am J Neuroradiol. 2003;24(10):1989-98.

16. Law M, Young RJ, Babb JS, Peccerelli N, Chheang S, Gruber ML, et al. Gliomas: predicting time to progression or survival with cerebral blood volume measurements at dynamic susceptibilityweighted contrast-enhanced perfusion MR imaging. Radiology. 2008;247(2):490-8.

17. Danchaivijitr N, Waldman AD, Tozer DJ, Benton CE, Brasil Caseiras $\mathrm{G}$, Tofts PS, et al. Low-grade gliomas: do changes in rCBV measurements at longitudinal perfusion-weighted MR imaging predict malignant transformation? Radiology. 2008;247(1):170-8.

18. Schmainda KM, Zhang Z, Prah M, Snyder BS, Gilbert MR, Sorensen AG, et al. Dynamic susceptibility contrast MRI measures of relative cerebral blood volume as a prognostic marker for overall survival in recurrent glioblastoma: results from the ACRIN 6677/RTOG 0625 multicenter trial. Neuro-Oncology. 2015;17(8):1148-56.

19. Kickingereder P, Sahm F, Radbruch A, Wick W, Heiland S, Deimling A, et al. IDH mutation status is associated with a distinct hypoxia/angiogenesis transcriptome signature which is noninvasively predictable with $\mathrm{rCBV}$ imaging in human glioma. Sci Rep. 2015;5:16238.
20. Hu LS, Ning S, Eschbacher JM, Baxter LC, Gaw N, Ranjbar S, et al. Radiogenomics to characterize regional genetic heterogeneity in glioblastoma. Neuro-Oncology. 2017;19(1):128-37.

21. Ostergaard L. Principles of cerebral perfusion imaging by bolus tracking. J Magn Reson Imaging. 2005;22(6):710-7.

22. Verma N, Cowperthwaite MC, Burnett MG, Markey MK. Differentiating tumor recurrence from treatment necrosis: a review of neuro-oncologic imaging strategies. Neuro-Oncology. 2013;15(5):515-34.

23. Suh CH, Kim HS, Choi YJ, Kim N, Kim SJ. Prediction of pseudoprogression in patients with glioblastomas using the initial and final area under the curves ratio derived from dynamic contrast-enhanced T1-weighted perfusion MR imaging. AJNR Am J Neuroradiol. 2013;34(12):2278-86.

24. Ye J, Bhagat SK, Li H, Luo X, Wang B, Liu L, et al. Differentiation between recurrent gliomas and radiation necrosis using arterial spin labeling perfusion imaging. Exp Ther Med. 2016;11(6):2432-6.

25. Golay X, Petersen ET. Arterial spin labeling: benefits and pitfalls of high magnetic field. Neuroimaging Clin N Am. 2006;16(2): 259-68 x.

26. Lu D, Pavlakis SG, Frank Y, Bakshi S, Pahwa S, Gould RJ, et al. Proton MR spectroscopy of the basal ganglia in healthy children and children with AIDS. Radiology. 1996;199(2):423-8.

27. Howe FA, Barton SJ, Cudlip SA, Stubbs M, Saunders DE, Murphy M, et al. Metabolic profiles of human brain tumors using quantitative in vivo $1 \mathrm{H}$ magnetic resonance spectroscopy. Magn Reson Med. 2003;49(2):223-32.

28. Miller BL. A review of chemical issues in 1H NMR spectroscopy: $\mathrm{N}$-acetyl-L-aspartate, creatine and choline. NMR Biomed. 1991;4(2):47-52.

29. Kamada K, Houkin K, Abe H, Sawamura Y, Kashiwaba T. Differentiation of cerebral radiation necrosis from tumor recurrence by proton magnetic resonance spectroscopy. Neurol Med Chir (Tokyo). 1997;37(3):250-6.

30. Urenjak J, Williams SR, Gadian DG, Noble M. Specific expression of $\mathrm{N}$-acetylaspartate in neurons, oligodendrocyte-type-2 astrocyte progenitors, and immature oligodendrocytes in vitro. $\mathrm{J}$ Neurochem. 1992;59(1):55-61.

31. Tallan HH. Studies on the distribution of N-acetyl-L-aspartic acid in brain. J Biol Chem. 1957;224(1):41-5.

32. Dhermain FG, Hau P, Lanfermann H, Jacobs AH, van den Bent MJ. Advanced MRI and PET imaging for assessment of treatment response in patients with gliomas. Lancet Neurol. 2010;9(9):906-20.

33. Ferda J, Ferdová E, Hes O, Mraček J, Kreuzberg B, Baxa J. PET/ MRI: multiparametric imaging of brain tumors. Eur J Radiol. 2017;94:A14-a25.

34. Pouwels PJ, Kruse B, Korenke GC, Mao X, Hanefeld FA, Frahm J. Quantitative proton magnetic resonance spectroscopy of childhood adrenoleukodystrophy. Neuropediatrics. 1998;29(5):254-64.

35. Kantarci K, Knopman DS, Dickson DW, Parisi JE, Whitwell JL, Weigand SD, et al. Alzheimer disease: postmortem neuropathologic correlates of antemortem $1 \mathrm{H}$ MR spectroscopy metabolite measurements. Radiology. 2008;248(1):210-20.

36. Choi C, Raisanen JM, Ganji SK, Zhang S, McNeil SS, An Z, et al. Prospective longitudinal analysis of 2-hydroxyglutarate magnetic resonance spectroscopy identifies broad clinical utility for the management of patients with IDH-mutant glioma. J Clin Oncol. 2016;34(33):4030-9.

37. Wilson M, Andronesi O, Barker PB, Bartha R, Bizzi A, Bolan PJ, et al. Methodological consensus on clinical proton MRS of the brain: review and recommendations. Magn Reson Med. 2019;82(2):527-50.

38. Leao DJ, Craig PG, Godoy LF, Leite CC, Policeni B. Response Assessment in neuro-oncology criteria for gliomas: practical 
approach using conventional and advanced techniques. AJNR Am J Neuroradiol. 2020;41(1):10-20.

39. Li X, Strasser B, Jafari-Khouzani K, Thapa B, Small J, Cahill DP, et al. Super-resolution whole-brain 3D MR spectroscopic imaging for mapping D-2-hydroxyglutarate and tumor metabolism in isocitrate dehydrogenase 1-mutated human gliomas. Radiology. 2020;294(3):589-97.

40. Hourani R, Brant LJ, Rizk T, Weingart JD, Barker PB, Horská A. Can proton MR spectroscopic and perfusion imaging differentiate between neoplastic and nonneoplastic brain lesions in adults? AJNR Am J Neuroradiol. 2008;29(2):366-72.

41. Kazda T, Bulik M, Pospisil P, Lakomy R, Smrcka M, Slampa P, et al. Advanced MRI increases the diagnostic accuracy of recurrent glioblastoma: single institution thresholds and validation of MR spectroscopy and diffusion weighted MR imaging. Neuroimage Clin. 2016;11:316-21.

42. Bulik M, Kazda T, Slampa P, Jancalek R. The diagnostic ability of follow-up imaging biomarkers after treatment of glioblastoma in the temozolomide era: implications from proton MR spectroscopy and apparent diffusion coefficient mapping. Biomed Res Int. 2015;2015:641023.

43. Zhang H, Ma L, Wang Q, Zheng X, Wu C, Xu BN. Role of magnetic resonance spectroscopy for the differentiation of recurrent glioma from radiation necrosis: a systematic review and metaanalysis. Eur J Radiol. 2014;83(12):2181-9.

44. Lohmann P, Kocher M, Ceccon G, Bauer EK, Stoffels G, Viswanathan S, et al. Combined FET PET/MRI radiomics differentiates radiation injury from recurrent brain metastasis. Neuroimage Clin. 2018;20:537-42.

45. Lohmann P, Kocher M, Steger J, Galldiks N. Radiomics derived from amino-acid PET and conventional MRI in patients with highgrade gliomas. Q J Nucl Med Mol Imaging. 2018;62(3):272-80.

46. Jena A, Taneja S, Gambhir A, Mishra AK, D souza MM, Verma SM, et al. Glioma recurrence versus radiation necrosis: single-session multiparametric approach using simultaneous O-(2-18F-fluoroethyl)L-tyrosine PET/MRI. Clin Nucl Med. 2016;41(5):e228-36.

47. Wijnen JP, Idema AJ, Stawicki M, Lagemaat MW, Wesseling P, Wright AJ, et al. Quantitative short echo time 1H MRSI of the peripheral edematous region of human brain tumors in the differentiation between glioblastoma, metastasis, and meningioma. $\mathrm{J}$ Magn Reson Imaging. 2012;36(5):1072-82.

48. Chawla S, Zhang Y, Wang S, Chaudhary S, Chou C, O'Rourke $\mathrm{DM}$, et al. Proton magnetic resonance spectroscopy in differentiating glioblastomas from primary cerebral lymphomas and brain metastases. J Comput Assist Tomogr. 2010;34(6):836-41.

49. Julià-Sapé M, Coronel I, Majós C, Candiota AP, Serrallonga M, $\operatorname{Cos} \mathrm{M}$, et al. Prospective diagnostic performance evaluation of single-voxel $1 \mathrm{H}$ MRS for typing and grading of brain tumours. NMR Biomed. 2012;25(4):661-73.

50. Anbarloui MR, Ghodsi SM, Khoshnevisan A, Khadivi M, Abdollahzadeh S, Aoude A, et al. Accuracy of magnetic resonance spectroscopy in distinction between radiation necrosis and recurrence of brain tumors. Iran J Neurol. 2015;14(1):29-34.

51. Rock JP, Hearshen D, Scarpace L, Croteau D, Gutierrez J, Fisher $\mathrm{JL}$, et al. Correlations between magnetic resonance spectroscopy and image-guided histopathology, with special attention to radiation necrosis. Neurosurgery. 2002;51(4):912-9 discussion 9-20.

52. Hygino da Cruz LC Jr, Rodriguez I, Domingues RC, Gasparetto EL, Sorensen AG. Pseudoprogression and pseudoresponse: imaging challenges in the assessment of posttreatment glioma. AJNR Am J Neuroradiol. 2011;32(11):1978-85.

53. Guo AC, Cummings TJ, Dash RC, Provenzale JM. Lymphomas and high-grade astrocytomas: comparison of water diffusibility and histologic characteristics. Radiology. 2002;224(1):177-83.

54. Higano S, Yun X, Kumabe T, Watanabe M, Mugikura S, Umetsu A, et al. Malignant astrocytic tumors: clinical importance of apparent diffusion coefficient in prediction of grade and prognosis. Radiology. 2006;241(3):839-46.

55. Oberheim Bush NA, Hervey-Jumper SL, Berger MS. Management of glioblastoma, present and future. World Neurosurg. 2019;131:328-38.

56. Pirzkall A, McGue C, Saraswathy S, Cha S, Liu R, Vandenberg S, et al. Tumor regrowth between surgery and initiation of adjuvant therapy in patients with newly diagnosed glioblastoma. NeuroOncology. 2009;11(6):842-52.

57. Hamstra DA, Galbán CJ, Meyer CR, Johnson TD, Sundgren PC, Tsien C, et al. Functional diffusion map as an early imaging biomarker for high-grade glioma: correlation with conventional radiologic response and overall survival. J Clin Oncol. 2008;26(20):3387-94.

58. Moffat BA, Chenevert TL, Lawrence TS, Meyer CR, Johnson TD, Dong Q, et al. Functional diffusion map: a noninvasive MRI biomarker for early stratification of clinical brain tumor response. Proc Natl Acad Sci U S A. 2005;102(15):5524-9.

59. Pope WB, Kim HJ, Huo J, Alger J, Brown MS, Gjertson D, et al. Recurrent glioblastoma multiforme: ADC histogram analysis predicts response to bevacizumab treatment. Radiology. 2009;252(1):182-9.

60. Mong S, Ellingson BM, Nghiemphu PL, Kim HJ, Mirsadraei L, Lai A, et al. Persistent diffusion-restricted lesions in bevacizumabtreated malignant gliomas are associated with improved survival compared with matched controls. AJNR Am J Neuroradiol. 2012;33(9):1763-70.

61. Nguyen HS, Milbach N, Hurrell SL, Cochran E, Connelly J, Bovi JA, et al. Progressing bevacizumab-induced diffusion restriction is associated with coagulative necrosis surrounded by viable tumor and decreased overall survival in patients with recurrent glioblastoma. AJNR Am J Neuroradiol. 2016;37(12):2201-8.

62. Zhang H, Ma L, Shu C, Wang YB, Dong LQ. Diagnostic accuracy of diffusion MRI with quantitative ADC measurements in differentiating glioma recurrence from radiation necrosis. J Neurol Sci. 2015;351(1-2):65-71.

63. Prager AJ, Martinez N, Beal K, Omuro A, Zhang Z, Young RJ. Diffusion and perfusion MRI to differentiate treatment-related changes including pseudoprogression from recurrent tumors in high-grade gliomas with histopathologic evidence. AJNR Am J Neuroradiol. 2015;36(5):877-85.

64. Van Cauter S, Veraart J, Sijbers J, Peeters RR, Himmelreich U, De Keyzer F, et al. Gliomas: diffusion kurtosis MR imaging in grading. Radiology. 2012;263(2):492-501.

65. Alexander AL, Lee JE, Lazar M, Field AS. Diffusion tensor imaging of the brain. Neurotherapeutics. 2007;4(3):316-29.

66. Jensen JH, Helpern JA. MRI quantification of non-Gaussian water diffusion by kurtosis analysis. NMR Biomed. 2010;23(7):698710.

67. Raab P, Hattingen E, Franz K, Zanella FE, Lanfermann H. Cerebral gliomas: diffusional kurtosis imaging analysis of microstructural differences. Radiology. 2010;254(3):876-81.

68. Falk Delgado A, Nilsson M, van Westen D, Falk DA. Glioma grade discrimination with MR diffusion kurtosis imaging: a meta-analysis of diagnostic accuracy. Radiology. 2018;287(1): 119-27.

69. Huang R, Chen Y, Li W, Zhang X. An evidence-based approach to assess the accuracy of diffusion kurtosis imaging in characterization of gliomas. Medicine (Baltimore). 2018;97(44):e13068.

70. Abdalla G, Dixon L, Sanverdi E, Machado PM, Kwong JSW, Panovska-Griffiths J, et al. The diagnostic role of diffusional kurtosis imaging in glioma grading and differentiation of gliomas from other intra-axial brain tumours: a systematic review with critical appraisal and meta-analysis. Neuroradiology. 2020;62(7): 791-802.

71. Wen Q, Kelley DA, Banerjee S, Lupo JM, Chang SM, Xu D, et al. Clinically feasible NODDI characterization of glioma using multiband EPI at 7T. Neuroimage Clin. 2015;9:291-9. 
72. Zhou J, Lal B, Wilson DA, Laterra J, van Zijl PC. Amide proton transfer (APT) contrast for imaging of brain tumors. Magn Reson Med. 2003;50(6):1120-6.

73. van Zijl PC, Yadav NN. Chemical exchange saturation transfer (CEST): what is in a name and what isn't? Magn Reson Med. 2011;65(4):927-48.

74. Wu B, Warnock G, Zaiss M, Lin C, Chen M, Zhou Z, et al. An overview of CEST MRI for non-MR physicists. EJNMMI Phys. 2016;3(1):19.

75. Ward KM, Aletras AH, Balaban RS. A new class of contrast agents for MRI based on proton chemical exchange dependent saturation transfer (CEST). J Magn Reson. 2000;143(1):79-87.

76. Dou W, Lin CE, Ding H, Shen Y, Dou C, Qian L, et al. Chemical exchange saturation transfer magnetic resonance imaging and its main and potential applications in pre-clinical and clinical studies. Quant Imaging Med Surg. 2019;9(10):1747-66.

77. Zhou J, Payen JF, Wilson DA, Traystman RJ, van Zijl PC. Using the amide proton signals of intracellular proteins and peptides to detect $\mathrm{pH}$ effects in MRI. Nat Med. 2003;9(8):1085-90.

78. Yan K, Fu Z, Yang C, Zhang K, Jiang S, Lee DH, et al. Assessing amide proton transfer (APT) MRI contrast origins in 9L gliosarcoma in the rat brain using proteomic analysis. Mol Imaging Biol. 2015;17(4):479-87.

79. Chan KW, McMahon MT, Kato Y, Liu G, Bulte JW, Bhujwalla $\mathrm{ZM}$, et al. Natural D-glucose as a biodegradable MRI contrast agent for detecting cancer. Magn Reson Med. 2012;68(6):1764-73.

80. Xu X, Yadav NN, Knutsson L, Hua J, Kalyani R, Hall E, et al. Dynamic glucose-enhanced (DGE) MRI: translation to human scanning and first results in glioma patients. Tomography. 2015;1(2):105-14.

81. Zaiss M, Windschuh J, Goerke S, Paech D, Meissner JE, Burth S, et al. Downfield-NOE-suppressed amide-CEST-MRI at 7 Tesla provides a unique contrast in human glioblastoma. Magn Reson Med. 2017;77(1):196-208.

82. Regnery S, Adeberg S, Dreher C, Oberhollenzer J, Meissner JE, Goerke S, et al. Chemical exchange saturation transfer MRI serves as predictor of early progression in glioblastoma patients. Oncotarget. 2018;9(47):28772-83.

83. Goerke S, Milde KS, Bukowiecki R, Kunz P, Klika KD, Wiglenda $\mathrm{T}$, et al. Aggregation-induced changes in the chemical exchange saturation transfer (CEST) signals of proteins. NMR Biomed. 2017;30(1).

84. Zaiss M, Kunz P, Goerke S, Radbruch A, Bachert P. MR imaging of protein folding in vitro employing nuclear-Overhauser-mediated saturation transfer. NMR Biomed. 2013;26(12):1815-22.

85. Jones CK, Schlosser MJ, van Zijl PC, Pomper MG, Golay X, Zhou J. Amide proton transfer imaging of human brain tumors at 3T. Magn Reson Med. 2006;56(3):585-92.

86. Wen Z, Hu S, Huang F, Wang X, Guo L, Quan X, et al. MR imaging of high-grade brain tumors using endogenous protein and peptide-based contrast. Neuroimage. 2010;51(2):616-22.

87. Jiang S, Eberhart CG, Zhang Y, Heo HY, Wen Z, Blair L, et al. Amide proton transfer-weighted magnetic resonance imageguided stereotactic biopsy in patients with newly diagnosed gliomas. Eur J Cancer. 2017;83:9-18.

88. Zhou J, Zhu H, Lim M, Blair L, Quinones-Hinojosa A, Messina $\mathrm{SA}$, et al. Three-dimensional amide proton transfer MR imaging of gliomas: initial experience and comparison with gadolinium enhancement. J Magn Reson Imaging. 2013;38(5):1119-28.

89. Togao O, Yoshiura T, Keupp J, Hiwatashi A, Yamashita K, Kikuchi K, et al. Amide proton transfer imaging of adult diffuse gliomas: correlation with histopathological grades. NeuroOncology. 2014;16(3):441-8.

90. Ma B, Blakeley JO, Hong X, Zhang H, Jiang S, Blair L, et al. Applying amide proton transfer-weighted MRI to distinguish pseudoprogression from true progression in malignant gliomas. $\mathrm{J}$ Magn Reson Imaging. 2016;44(2):456-62.

91. Park KJ, Kim HS, Park JE, Shim WH, Kim SJ, Smith SA. Added value of amide proton transfer imaging to conventional and perfusion MR imaging for evaluating the treatment response of newly diagnosed glioblastoma. Eur Radiol. 2016;26(12):4390-403.

92. Desmond KL, Mehrabian H, Chavez S, Sahgal A, Soliman H, Rola R, et al. Chemical exchange saturation transfer for predicting response to stereotactic radiosurgery in human brain metastasis. Magn Reson Med. 2017;78(3):1110-20.

93. Mehrabian H, Myrehaug S, Soliman H, Sahgal A, Stanisz GJ. Evaluation of Glioblastoma Response to Therapy With Chemical Exchange Saturation Transfer. Int J Radiat Oncol Biol Phys. 2018;101(3):713-23.

94. Jiang S, Rui Q, Wang Y, Heo HY, Zou T, Yu H, et al. Discriminating MGMT promoter methylation status in patients with glioblastoma employing amide proton transfer-weighted MRI metrics. Eur Radiol. 2018;28(5):2115-23.

95. Jiang S, Zou T, Eberhart CG, Villalobos MAV, Heo HY, Zhang $\mathrm{Y}$, et al. Predicting IDH mutation status in grade II gliomas using amide proton transfer-weighted (APTw) MRI. Magn Reson Med. 2017;78(3):1100-9.

96. Kumar VA, Heiba IM, Prabhu SS, Chen MM, Colen RR, Young $\mathrm{AL}$, et al. The role of resting-state functional MRI for clinical preoperative language mapping. Cancer Imaging. 2020;20(1):47.

97. Park KY, Lee JJ, Dierker D, Marple LM, Hacker CD, Roland JL, et al. Mapping language function with task-based vs. resting-state functional MRI. PLoS One. 2020;15(7):e0236423.

98. Hua J, Miao X, Agarwal S, Bettegowda C, Quiñones-Hinojosa A, Laterra J, et al. Language mapping using T2-prepared BOLD functional MRI in the Presence of large susceptibility artifactsinitial results in patients with brain tumor and epilepsy. Tomography. 2017;3(2):105-13.

99. Silva MA, See AP, Essayed WI, Golby AJ, Tie Y. Challenges and techniques for presurgical brain mapping with functional MRI. Neuroimage Clin. 2018;17:794-803.

100. Morrison MA, Tam F, Garavaglia MM, Hare GM, Cusimano MD, Schweizer TA, et al. Sources of variation influencing concordance between functional MRI and direct cortical stimulation in brain tumor surgery. Front Neurosci. 2016;10:461.

101. Stopa BM, Senders JT, Broekman MLD, Vangel M, Golby AJ. Preoperative functional MRI use in neurooncology patients: a clinician survey. Neurosurg Focus. 2020;48(2):E11.

102. Henderson F, Abdullah KG, Verma R, Brem S. Tractography and the connectome in neurosurgical treatment of gliomas: the premise, the progress, and the potential. Neurosurg Focus. 2020;48(2):E6.

103. Verburg N, de Witt Hamer PC. State-of-the-art imaging for glioma surgery. Neurosurg Rev. 2020.

104. Albert NL, Weller M, Suchorska B, Galldiks N, Soffietti R, Kim $\mathrm{MM}$, et al. Response assessment in Neuro-Oncology working group and European Association for Neuro-Oncology recommendations for the clinical use of PET imaging in gliomas. NeuroOncology. 2016;18(9):1199-208.

105. Galldiks N, Langen KJ, Albert NL, Chamberlain M, Soffietti R, Kim MM, et al. PET imaging in patients with brain metastasisreport of the RANO/PET group. Neuro-Oncology. 2019;21(5): 585-95.

106. Özütemiz C, Neil EC, Tanwar M, Rubin NT, Ozturk K, Cayci Z. The role of dual-phase FDG PET/CT in the diagnosis and followup of brain tumors. AJR Am J Roentgenol. 2020:1-12.

107. Hatzoglou V, Yang TJ, Omuro A, Gavrilovic I, Ulaner G, Rubel J, et al. A prospective trial of dynamic contrast-enhanced MRI perfusion and fluorine-18 FDG PET-CT in differentiating brain tumor progression from radiation injury after cranial irradiation. NeuroOncology. 2016;18(6):873-80. 
108. Ozsunar Y, Mullins ME, Kwong K, Hochberg FH, Ament C, Schaefer PW, et al. Glioma recurrence versus radiation necrosis? A pilot comparison of arterial spin-labeled, dynamic susceptibility contrast enhanced MRI, and FDG-PET imaging. Acad Radiol. 2010;17(3):282-90.

109. Hojjati M, Badve C, Garg V, Tatsuoka C, Rogers L, Sloan A, et al. Role of FDG-PET/MRI, FDG-PET/CT, and dynamic susceptibility contrast perfusion MRI in differentiating radiation necrosis from tumor recurrence in glioblastomas. J Neuroimaging. 2018;28(1):118-25.

110. Jena A, Taneja S, Jha A, Damesha NK, Negi P, Jadhav GK, et al. Multiparametric evaluation in differentiating glioma recurrence from treatment-induced necrosis using simultaneous (18)F-FDGPET/MRI: a single-institution retrospective study. AJNR Am J Neuroradiol. 2017;38(5):899-907.

111. Seligman L, Kovanlikaya I, Pisapia DJ, Naeger DM, Magge R, Fine HA, et al. Integrated PET-MRI for Glioma surveillance: perfusion-metabolism discordance rate and association with molecular profiling. AJR Am J Roentgenol. 2019;212(4):883-91.

112. Pyatigorskaya N, Sgard B, Bertaux M, Yahia-Cherif L, Kas A. Can FDG-PET/MR help to overcome limitations of sequential MRI and PET-FDG for differential diagnosis between recurrence/progression and radionecrosis of high-grade gliomas? J Neuroradiol. 2020.

113. Law I, Albert NL, Arbizu J, Boellaard R, Drzezga A, Galldiks N, et al. Joint EANM/EANO/RANO practice guidelines/SNMMI procedure standards for imaging of gliomas using PET with radiolabelled amino acids and [(18)F]FDG: version 1.0. Eur J Nucl Med Mol Imaging. 2019;46(3):540-57.

114. Werner JM, Lohmann P, Fink GR, Langen KJ, Galldiks N. Current landscape and emerging fields of PET imaging in patients with brain tumors. Molecules. 2020;25(6).

115. Stegmayr C, Stoffels G, Filss C, Heinzel A, Lohmann P, Willuweit A, et al. Current trends in the use of O-(2[(18)F]fluoroethyl)-L-tyrosine ([(18)F]FET) in neurooncology. Nucl Med Biol. 2020.

116. Lohmann P, Werner JM, Shah NJ, Fink GR, Langen KJ, Galldiks N. Combined amino acid positron emission tomography and advanced magnetic resonance imaging in glioma patients. Cancers (Basel). 2019;11(2).

117. Langen KJ, Hamacher K, Weckesser M, Floeth F, Stoffels G, Bauer $\mathrm{D}$, et al. O-(2-[18F]fluoroethyl)-L-tyrosine: uptake mechanisms and clinical applications. Nucl Med Biol. 2006;33(3):287-94.

118. Galldiks N, Law I, Pope WB, Arbizu J, Langen KJ. The use of amino acid PET and conventional MRI for monitoring of brain tumor therapy. Neuroimage Clin. 2017;13:386-94.

119. Galldiks N, Dunkl V, Stoffels G, Hutterer M, Rapp M, Sabel M, et al. Diagnosis of pseudoprogression in patients with glioblastoma using O-(2-[18F]fluoroethyl)-L-tyrosine PET. Eur J Nucl Med Mol Imaging. 2015;42(5):685-95.

120. Heinzel A, Muller D, Yekta-Michael SS, Ceccon G, Langen KJ, Mottaghy FM, et al. O-(2-18F-fluoroethyl)-L-tyrosine PET for evaluation of brain metastasis recurrence after radiotherapy: an effectiveness and cost-effectiveness analysis. Neuro-Oncology. 2017;19(9):1271-8.

121. Habermeier A, Graf J, Sandhofer BF, Boissel JP, Roesch F, Closs EI. System L amino acid transporter LAT1 accumulates O-(2fluoroethyl)-L-tyrosine (FET). Amino Acids. 2015;47(2):335-44.

122. Nawashiro H, Otani N, Uozumi Y, Ooigawa H, Toyooka T, Suzuki $\mathrm{T}$, et al. High expression of L-type amino acid transporter 1 in infiltrating glioma cells. Brain Tumor Pathol. 2005;22(2):89-91.

123. Haining Z, Kawai N, Miyake K, Okada M, Okubo S, Zhang X, et al. Relation of LAT1/4F2hc expression with pathological grade, proliferation and angiogenesis in human gliomas. BMC Clin Pathol. 2012;12:4.
124. Ceccon G, Lohmann P, Stoffels G, Judov N, Filss CP, Rapp M, et al. Dynamic O-(2-18F-fluoroethyl)-L-tyrosine positron emission tomography differentiates brain metastasis recurrence from radiation injury after radiotherapy. Neuro-Oncology. 2017;19(2):281-8.

125. Pyka T, Gempt J, Ringel F, Huttinger S, van Marwick S, Nekolla S, et al. Prediction of glioma recurrence using dynamic (1)(8)Ffluoroethyltyrosine PET. AJNR Am J Neuroradiol. 2014;35(10): 1924-9.

126. Göttler J, Lukas M, Kluge A, Kaczmarz S, Gempt J, Ringel F, et al. Intra-lesional spatial correlation of static and dynamic FETPET parameters with MRI-based cerebral blood volume in patients with untreated glioma. Eur J Nucl Med Mol Imaging. 2017;44(3):392-7.

127. Galldiks N, Stoffels G, Filss CP, Piroth MD, Sabel M, Ruge MI, et al. Role of O-(2-(18)F-fluoroethyl)-L-tyrosine PET for differentiation of local recurrent brain metastasis from radiation necrosis. J Nucl Med. 2012;53(9):1367-74.

128. Romagna A, Unterrainer M, Schmid-Tannwald C, Brendel M, Tonn JC, Nachbichler SB, et al. Suspected recurrence of brain metastases after focused high dose radiotherapy: can [(18)F]FET- PET overcome diagnostic uncertainties? Radiat Oncol. 2016;11(1):139.

129. Lundemann M, Munck Af Rosenschold P, Muhic A, Larsen VA, Poulsen HS, Engelholm SA, et al. Feasibility of multi-parametric PET and MRI for prediction of tumour recurrence in patients with glioblastoma. Eur J Nucl Med Mol Imaging. 2019;46(3):603-13.

130. Floeth FW, Pauleit D, Wittsack HJ, Langen KJ, Reifenberger G, Hamacher K, et al. Multimodal metabolic imaging of cerebral gliomas: positron emission tomography with [18F]fluoroethyl-Ltyrosine and magnetic resonance spectroscopy. J Neurosurg. 2005;102(2):318-27.

131. D'Souza MM, Sharma R, Jaimini A, Panwar P, Saw S, Kaur P, et al. 11C-MET PET/CT and advanced MRI in the evaluation of tumor recurrence in high-grade gliomas. Clin Nucl Med. 2014;39(9):791-8.

132. Jena A, Taneja S, Gambhir A, Mishra AK, D'Souza MM, Verma $\mathrm{SM}$, et al. Glioma recurrence versus radiation necrosis: singlesession multiparametric approach using simultaneous $\mathrm{O}-(2-18 \mathrm{~F}-$ Fluoroethyl)-L-tyrosine PET/MRI. Clin Nucl Med. 2016;41(5): e228-36.

133. Mauler J, Maudsley AA, Langen KJ, Nikoubashman O, Stoffels $\mathrm{G}$, Sheriff S, et al. Spatial relationship of glioma volume derived from (18)F-FET PET and volumetric MR spectroscopy imaging: a hybrid PET/MRI study. J Nucl Med. 2018;59(4):603-9.

134. Stadlbauer A, Prante O, Nimsky C, Salomonowitz E, Buchfelder $\mathrm{M}$, Kuwert T, et al. Metabolic imaging of cerebral gliomas: spatial correlation of changes in O-(2-18F-fluoroethyl)-L-tyrosine PET and proton magnetic resonance spectroscopic imaging. J Nucl Med. 2008;49(5):721-9.

135. Popp I, Bott S, Mix M, Oehlke O, Schimek-Jasch T, Nieder C, et al. Diffusion-weighted MRI and ADC versus FET-PET and GdT1w-MRI for gross tumor volume (GTV) delineation in reirradiation of recurrent glioblastoma. Radiother Oncol. 2019;130:121-31.

136. da Silva NA, Lohmann P, Fairney J, Magill AW, Oros Peusquens AM, Choi CH, et al. Hybrid MR-PET of brain tumours using amino acid PET and chemical exchange saturation transfer MRI. Eur J Nucl Med Mol Imaging. 2018;45(6):1031-40.

137. Schon S, Cabello J, Liesche-Starnecker F, Molina-Romero M, Eichinger P, Metz M, et al. Imaging glioma biology: spatial comparison of amino acid PET, amide proton transfer, and perfusionweighted MRI in newly diagnosed gliomas. Eur J Nucl Med Mol Imaging. 2020;47(6):1468-75.

138. Filss CP, Galldiks N, Stoffels G, Sabel M, Wittsack HJ, Turowski B, et al. Comparison of 18F-FET PET and perfusion-weighted 
MR imaging: a PET/MR imaging hybrid study in patients with brain tumors. J Nucl Med. 2014;55(4):540-5.

139. Henriksen OM, Larsen VA, Muhic A, Hansen AE, Larsson HBW, Poulsen HS, et al. Simultaneous evaluation of brain tumour metabolism, structure and blood volume using [(18)F]fluoroethyltyrosine (FET) PET/MRI: feasibility, agreement and initial experience. Eur J Nucl Med Mol Imaging. 2016;43(1): 103-12.

140. Sogani SK, Jena A, Taneja S, Gambhir A, Mishra AK, D'Souza $\mathrm{MM}$, et al. Potential for differentiation of glioma recurrence from radionecrosis using integrated (18)F-fluoroethyl-L-tyrosine (FET) positron emission tomography/magnetic resonance imaging: a prospective evaluation. Neurol India. 2017;65(2):293-301.

141. Pyka T, Hiob D, Preibisch C, Gempt J, Wiestler B, Schlegel J, et al. Diagnosis of glioma recurrence using multiparametric dynamic 18F-fluoroethyl-tyrosine PET-MRI. Eur J Radiol. 2018;103:32-7.

142. Verger A, Filss CP, Lohmann P, Stoffels G, Sabel M, Wittsack HJ, et al. Comparison of (18)F-FET PET and perfusion-weighted MRI for glioma grading: a hybrid PET/MR study. Eur J Nucl Med Mol Imaging. 2017;44(13):2257-65.

143. Verger A, Filss CP, Lohmann P, Stoffels G, Sabel M, Wittsack HJ, et al. Comparison of O-(2-(18)F-fluoroethyl)-L-tyrosine positron emission tomography and perfusion-weighted magnetic resonance imaging in the diagnosis of patients with progressive and recurrent glioma: a hybrid positron emission tomography/magnetic resonance study. World Neurosurg. 2018;113:e727-e37.

144. Chang SM, Wen PY, Vogelbaum MA, Macdonald DR, van den Bent MJ. Response assessment in Neuro-Oncology (RANO): more than imaging criteria for malignant glioma. Neurooncol Pract. 2015;2(4):205-9.

145. Molinaro AM, Hervey-Jumper S, Morshed RA, Young J, Han SJ, Chunduru P, et al. Association of maximal extent of resection of contrast-enhanced and non-contrast-enhanced tumor with survival within molecular subgroups of patients with newly diagnosed glioblastoma. JAMA Oncol. 2020;6(4):495-503.

146. Song S, Cheng Y, Ma J, Wang L, Dong C, Wei Y, et al. Simultaneous FET-PET and contrast-enhanced MRI based on hybrid PET/MR improves delineation of tumor spatial biodistribution in gliomas: a biopsy validation study. Eur J Nucl Med Mol Imaging. 2020.

147. Lohmann P, Stavrinou P, Lipke K, Bauer EK, Ceccon G, Werner $\mathrm{JM}$, et al. FET PET reveals considerable spatial differences in tumour burden compared to conventional MRI in newly diagnosed glioblastoma. Eur J Nucl Med Mol Imaging. 2019;46(3): 591-602.

148. Rizzo S, Botta F, Raimondi S, Origgi D, Fanciullo C, Morganti AG, et al. Radiomics: the facts and the challenges of image analysis. Eur Radiol Exp. 2018;2(1):36.

149. Mirchia K, Richardson TE. Beyond IDH-mutation: emerging molecular diagnostic and prognostic features in adult diffuse gliomas. Cancers (Basel). 2020;12(7).

150. Sasaki T, Kinoshita M, Fujita K, Fukai J, Hayashi N, Uematsu Y, et al. Radiomics and MGMT promoter methylation for prognostication of newly diagnosed glioblastoma. Sci Rep. 2019;9(1):14435.

151. Zhou M, Niu C, Jia L, He H. The value of MGMT promote methylation and IDH-1 mutation on diagnosis of pseudoprogression in patients with high-grade glioma: a metaanalysis. Medicine (Baltimore). 2019;98(50):e18194.

152. Gore S, Chougule T, Jagtap J, Saini J, Ingalhalikar M. A review of radiomics and deep predictive modeling in glioma characterization. Acad Radiol. 2020.

153. Chang P, Grinband J, Weinberg BD, Bardis M, Khy M, Cadena $\mathrm{G}$, et al. Deep-learning convolutional neural networks accurately classify genetic mutations in gliomas. AJNR Am J Neuroradiol. 2018;39(7):1201-7.

154. Lohmann P, Lerche C, Bauer EK, Steger J, Stoffels G, Blau T, et al. Predicting IDH genotype in gliomas using FET PET radiomics. Sci Rep. 2018;8(1):13328.

155. Haubold J, Demircioglu A, Gratz M, Glas M, Wrede K, Sure U, et al. Non-invasive tumor decoding and phenotyping of cerebral gliomas utilizing multiparametric (18)F-FET PET-MRI and MR fingerprinting. Eur J Nucl Med Mol Imaging. 2020;47(6):143545.

Publisher's Note Springer Nature remains neutral with regard to jurisdictional claims in published maps and institutional affiliations.

\section{Affiliations}

\section{Wynton B. Overcast ${ }^{1} \cdot$ Korbin M. Davis ${ }^{1} \cdot$ Chang Y. $\mathrm{Ho}^{2} \cdot$ Gary D. Hutchins ${ }^{3} \cdot$ Mark A. Green $^{3} \cdot$ Brian D. Graner ${ }^{2} \cdot$ Michael C. Veronesi ${ }^{4}$}

\section{Wynton B. Overcast}

wovercas@iu.edu

Korbin M. Davis

daviskom@iupui.edu

Chang Y. Ho

cyho@iu.edu

Gary D. Hutchins

gdhutchi@iupui.edu
Mark A. Green

magreen@iu.edu

Brian D. Graner

bgraner@iu.edu
1 Department of Radiology and Imaging Sciences, Indiana University School of Medicine, 550 N University Blvd. Room 0663, Indianapolis, IN 46202, USA
2 Department of Radiology and Imaging Sciences, Indiana University School of Medicine, Goodman Hall, 355 West 16th Street, Suite 4100, Indianapolis, IN 46202, USA 